\title{
Isomorphic Pressures and Innovation Trends in Italian Health Care Organizations
}

\author{
Stefania De Simone ${ }^{1}$ \\ ${ }^{1}$ Institute for Research on Innovation and Services for Development, National Research Council, Naples, Italy \\ Correspondence: Stefania De Simone, Institute for Research on Innovation and Services for Development, \\ National Research Council, Via G. Sanfelice, 8, 80134 Naples, Italy. E-mail: s.desimone@iriss.cnr.it
}

Received: March 17, 2017

Accepted: April 27, $2017 \quad$ Online Published: May 17, 2017

doi:10.5539/ijbm.v12n6p26

URL: https://doi.org/10.5539/ijbm.v12n6p26

\begin{abstract}
Over 20 years, hospitals in Italy as well as in other European countries have evolved and changed in response to institutional pressures. With the corporatization, there has been the entrance of new logics and governance structures that contributed to a transformation of the health system. The survival of healthcare organizations is dictated not only by the technical conditions, that allow efficiently and effectively operating, but also by the ability to comply with rules to get legitimacy from external institutional actors. Organizations in a population adapt to their environment, in which operate, so many other organizations adapting to it (isomorphism). The purpose of this paper is to discuss a theoretical framework based on neo-institutional approach that could explain the influence of isomorphic pressures on innovative processes in health care sector. Qualitative data from literature on neo-institutional theory applied to health care sector have been analyzed. Findings reveal institutional pressures stimulate the development of innovations and organizational learning. This concept concerns both the fit of the organization with its environment (strategic matters) and effective implementation of strategies. Hospitals must find ways to increase profit, by improving medical capabilities for payment health care services. One of the most important isomorphic pressure is the prospective payment system for health care that had effects on the choices of organizational models to adopt. The challenge for hospital administrators is to seek consistency between efficiency and quality care.
\end{abstract}

Keywords: hospital sector, innovation, institutional approach, isomorphism

\section{Introduction}

In all countries with advanced welfare systems, healthcare organizations operate in complex institutional systems, which define their space of autonomy in relation to health policy choices and affect their strategic choices, organizational design and management (De Simone, 2011a).

Over 20 years, hospitals in Italy as well as in other European countries have evolved and changed in response to institutional pressures. With the corporatization, there has been the entrance of new logics and governance structures that contributed to a transformation of the health system. The system of values began to incorporate new approaches and roles with a consequent distinction between productive and managerial dimension. New actors such as suppliers and intermediaries have arrived on the scene of health systems, leaving space to private organizations in the management of health services, and leading to a reconfiguration of traditional relationships and boundaries among actors. The need for rationalization was stimulated by a number of factors, such as the rising health care costs, due to the use of increasingly sophisticated technologies, the progressive aging of the population, the general rise in the cultural level of the population, which led to growing needs to meet (De Simone, 2011a).

The changes in political and institutional mechanisms, that define the resource allocation, and the increasing complexity of relationships among various stakeholders, internal and external to the organization, create new challenges to hospital administrators. Governments introduce measures to save costs, patients express growing demands, and citizens demand greater transparency on the functioning and resource utilization. This takes place in a context, where the main aim of improving patients' health status is not easy to quantify. Healthcare organizations must be able to develop appropriate traits of flexibility and innovation to deal with these pressures (De Simone 2011b). 
The institutional approach focuses on social processes of construction of reality, and how the existence of social interactions tends to stabilize reality through processes of legitimation and to define constraints on the range of possible actions, reducing the variability and unpredictability of individual behavior (De Simone, 2011b). This means considering the organization not as the product of the rational design, but as the result of institutional adaptation to the environment. Thus, an organization can adopt an innovation not just for the need to improve its performance, but to get legitimacy. Organizations in a population adapt to their environment, which is constituted by other organizations adapting to it (DiMaggio \& Powell, 1983). This reflects the tendency to isomorphism, useful concept to understand innovative processes in health sector.

Over the last decades, in Italy the vigorous policies of control of health expenditure by national and regional governments have led to profound changes in health systems. Some hospitals were closed, other hospitals have been merged and restructured, by showing their capability to respond to the institutional changes and innovate. One of the most important regulatory change is the adoption of new criteria to allocate public funds for the payment of health care. In the past, the national health fund was distributed to hospitals according to the spending of the previous year; nowadays hospitals receive a fixed amount based on diagnosis related group for each discharge (De Simone \& Siani, 2015).

\section{Purpose and Method}

The purpose of this paper is to discuss a theoretical framework based on neo-institutional approach that could explain the influence of isomorphic pressures on innovative processes in health care sector. The research question is: "The isomorphic pressures stimulate the development of innovations in health care organizations?

To answer the research question in this paper, qualitative data from literature on neo-institutional theory applied to health care sector have been analyzed. In particular, the concepts of organizational field, institutional logics, and isomorphic changes have been examined, in order to understand innovation trends in health care.

\section{Literary Review}

\subsection{The Organizational Field in the Neo-Institutional Approach}

The new institutionalism is a theoretical approach arisen in opposition to the approaches studying the economic systems only as the product of rational actions to achieve their goals. This approach revalues an important element of the environment: the set of rules, roles, beliefs that can influence organizational structures regardless of resource flows and requirements of technical nature.

The context in which organizations operate is composed of shared and ingrained cultural elements that act as template to organize activities (DiMaggio, 1991), and the modification of this template determines potential organizational changes.

If organizations want to survive, their organizational choices must consider external pressures (Oliver, 1991). An organizational form can be adopted not because it is more efficient in terms of transaction costs (Williamson, 1991) or adaptation through differentiation-integration (theory of structural contingencies), but because it is considered the appropriate way to organize activities as legitimized in the institutional context.

The organization, seen as the result of the adaptive process driven not by the rational management but by external factors (Scott, 1987), has a merely instrumental nature (Selznick, 1957). In choosing among alternative actions, managers prefer the one that conforms more to the standard of behavior, regardless of its convenience. Organizations often introduce performance assessment systems in order to appear legitimate towards influential external actors (De Simone, 2011b).

In the institutional approach, the analyses unit is the organizational field including different typologies of actors of a "recognized area of institutional life: key suppliers, resource and product consumers, regulatory agencies, and other organizations that produce similar services or products" (DiMaggio \& Powell, 1983: 148). In the health care field the main actors are: hospitals, health professionals, pharmaceutical companies (key suppliers); patients and potential patients (resource and product consumers); national and regional government, medical associations (regulatory agencies); medicine providers, social service provider (organization producing similar services or products) (Reay \& Hinings, 2005). The concept of field is interesting to link individual organizations to "populations" of organizations, and to examine the impact of common value and belief systems on organizational structures. Institutional pressures affect organizations, through processes taking place within the area.

Scott and Mayer (1983), taking up the distinction of Meyer and Rowan (1977) between organizations with independent criteria of efficiency and organizations that conform to exogenous requirements, distinguish the 
technical and institutional environment. The technical environment appears as a niche including a certain form of organization, by using the available resources and achieving a balance that allows its survival. The institutional environment refers to a set of norms and standards, to which organizations have to comply in order to get external legitimacy (Galvin, 2002).

In the case of health care, the technical environment includes factors affecting the demand and delivery of health services, the number and characteristics of supporting organizations, and inter-organizational "technical networks'.

The factors concerning the demand for health services in a defined area refer to the sociodemographic characteristics of the population, their preferences and lifestyles, and local economic conditions (unemployment rate). The variables regarding the delivery of health services include the number of health professionals and the public funds allocated to health services, infrastructure, training and coordination. The ability of organizations to provide services is influenced by both the introduction of new equipment and advanced clinical treatments, and the proliferation of information technologies, that facilitate the development of complex organizational and financial projects (De Simone, 2011a).

Supporting institutions, such as educational and professional associations, monitor service provision through the education and growth of professional capabilities of health care staff. The inter-organizational 'technical' networks link health care structures in vertical and horizontal systems, by increasing or reducing the resource allocation to the single structure.

The institutional environment is characterized by three types of variables: the actors; the dominant logics; and the government mechanisms. The actors can be part of the technical environment, if considered as producers and consumers of health services, and part of the institutional environment, if considered as bearers of institutional logics. The mechanisms of government are not endogenously imposed in the field, but they are the coding of the power structures and logics of the field (Abbott, 1988). The composition of government structures may change over time and, due to different potential sources of change, there can be no correspondence at a certain time between the change of the dominant institutional logics in the field and its government systems.

\subsection{Institutional Logics in Health Care Field}

The organizational principles of the field are institutional logics, referring not only to the cultural values (distinctions of interrelated systems, rules, values and norms), but also to the associated practices (rituals, routines and strategies used by the components of the field) that allow the adaptation and creation of cultural values (Friedland \& Alford, 1991).

These conceptions tend to emphasize that organizations operate within institutionally defined areas, and regulations guide the choice of the means (technology), and define the objectives of effectiveness and cost containment (Powell, 1991). Organizations and changes in social, political and economic values contribute to the spread of new institutional logics or ideologies (Davis, Diekmann, \& Tinsley, 1994).

The logic of managerial efficiency, generated and introduced by actors outside the "field", emphasizes the objectives of cost containment, profit, which prevail on quality, measured exclusively by medical professional standards, or on the typical criteria of public sector such as accessibility and fairness of treatment.

Patients and customers have redefined as consumers, medical professionals and health care organizations as providers, the health sector as an "industry", and the organizational choices are driven by the managerial rules. Managers have engaged in strategic planning, identification of cost and revenue centers, and creation of horizontal and vertical connection systems.

The "penetration" in the health care field of managerial logics, more intensely competing or contrasting professional standards, seems to have been facilitated by the introduction of logics emphasizing treatment equity in health care. The development of the latter logics, favored by the movements to protect consumers and by the alternative conceptions to medicine, have contributed to counter the dominance of medical professionalism, and create "space" within the field (De Simone, 2005).

Healthcare organizations are characterized more as an aggregate of different sub-systems, than as a unitary organizational system, with a low capacity to process unitary strategies both for the public importance of the provided services, which requires the development of actions consistent with regulatory requirements, and for many professional contributions in the organizations that require autonomy (De Simone, 2014).

Within healthcare organizations, forces of different nature coexist: the technical forces for patient care; and the institutional forces emphasizing criteria of efficiency in the service provision (Scott, 1995). 
The interaction between professional and managerial logics is a much discussed topic in the literature (Friedland \& Alford, 1991; Powell, 1991; Scott \& Meyer, 1983); on the one hand, it is assumed the antagonism of the two logics, and, on the other hand, it is argued that both logics can help to shape organizational activities. The professional logic follows a value system mainly focused on patient care, and the management logic adds to medical professional standards objectives of efficiency in service provision. Administrators must be able to coexist professional and managerial dimensions (De Simone, 2011a).

The survival of healthcare organizations is dictated not only by the technical conditions, that allow efficiently and effectively operating, but also by the ability to comply with rules in order to get legitimacy from external institutional actors. Thus, a challenge for managers is represented by the pursuit of consistency between ethical and economic principles. The ethic, viewed as attention to values and principles of individuals, affects the governance of health care system, by inspiring its mission. Managers having the responsibility to lead healthcare organizations should respect the constraints of efficiency and organizational effectiveness. The failure to comply with these constraints undermines the survival of the system itself (De Simone, 2011a).

\subsection{Structuring Versus Destructuring}

The structuring concerns the institutional process of modifications in types of actors, their interactions, and prevailing logics (DiMaggio \& Powell, 1983). The concept of duality structure-action of Giddens (1984) attempts to explain this process: the structures (rules and resources) impose constraints on individual actions, but at the same time make them possible. Individual actions, even if conditioned by the structures, are carriers of changes in the structures. There is a link between structures and actions: the former are made, strengthened, and changed through actions, and the latter assume significance only through structures.

De-structuring processes involve the breaking of existing beliefs and facilities due to competitive ideologies and coalitions of power. Since medical professionals interact with regulatory bodies, with consumer demands and with hospital administrators to legitimize the regulative and cognitive control, the consensus on institutional logics among the field components reduces. New organizational forms spread, some health providers disappeared and mingle, and other alternative providers multiply, with a consequent reduced clarity of connections within the field (Scott, Mendel \& Pollack, 1997).

The transformation process is characterized by status orders that change rapidly, as dominant actors previously lost power and prestige in favor of more specialized and flexible health systems. Health care providers suffer rapid change. According to Greenwood and Hining (1996), focusing on the interaction between organizational context and action, individual organizations keep, introduce or refuse a specific organizational tool, for the institutionalized nature of field in which operate. However, if the transformation process starts, it will be incremental and not revolutionary.

\subsection{Institutional Isomorphic Processes}

Once a set of organizations is structured in a defined organizational field, come into play powerful forces that lead to an increasing uniformity among the organizations of the field, uniformity described by the concept of isomorphism. Unlike the approaches of resource dependence and structural contingencies, the institutional approach highlights how the pressures of the institutional context tend to produce convergence in the organizational models adopted by organizations. Organizations tend, therefore, to adapt to the environment, complying with the expectations in terms of appropriate organizational model (Greenwood \& Hining, 1988) in order to obtain social legitimacy and improve their survivability. In a highly institutionalized sector, such as health care, which leads organizations to incorporate values, procedures or institutionalized practices (so-called rational myths) (Meyer \& Rowan, 1977), the need to create efficiency through "rational" design choices are contrasted by ceremonial rules that induce organizations to homogenize (isomorphism) as a result of coercion, mimetic behavior and professionalization (Powell \& DiMaggio, 1991).

Healthcare organizations could adopt advanced accounting and management tools not so much for a management need to rationally improve organizational performance, as because they expect the regulatory bodies (Ministry, and Regions) define resource allocation to favor organizations adopting advanced management tools (De Simone, 2011b).

DiMaggio and Powell (1983) recognize three forms of isomorphic changes. The first form, the coercive isomorphism, derived from both formal and informal pressures exerted on organizations by other influential organizations, and from cultural expectations existing within the field. Over the last decades, in health care sector the most important coercive change is the introduction of the prospective payment system for care services. The second form, the mimetic isomorphism, derives from the tendency of organizations to imitate other 
organizations, which are perceived as more legitimate or successful. In high uncertainty contexts, it is difficult to identify the causes of problems and possible solutions, so a strategy to adopt is to mimic another organization, saving research costs. An example of mimetic pressure is implementation of Total Quality management in the hospitals (Flood \& Fennel, 1995). The third form, the normative isomorphism, results from the presence of professionals within the organization. They suffer the same coercive and mimetic pressures of organizations, but more they suffer pressures from universities or educational institutions that tend to develop a common cognitive basis among specialists required to work in different organizations; associations and networks among professionals help to define and spread the "rules" of individual and organizational behaviors. In health sector, even if regulation reduced the dominance of physicians, their association still significantly affect strategic plans for care.

The isomorphism helps to legitimize the organization and increases its chances of survival. From a theoretical perspective, however, the trend is to prefer the analysis of inertia of organizational forms, and the change is primarily seen as a reproduction of the prevailing ways of thinking.

\section{Findings and Discussion}

In times of transformative environmental changes, only those organizations, matching their capabilities to the changing environment, will survive and learn. Organizations must find the way to get external legitimacy in order to achieve knowledge, financial and intellectual resources (Zimmerman \& Zeitz, 2002).

Over the past decades, the field of health services in Italy is characterized by a process of de-structuring with small attempts at restructuring, by the change of the previous institutional order and the introduction of new rules and structures. The new organizational forms bring different institutional logics and mechanisms of government and can provide new sources of structuring that led to de-structure previous traditional health providers. So hospitals or clinic shift from individual actors to networks. The boundaries among institutions, which first clearly defined the different matters of public intervention, or relationships between what takes on the community and what on individuals, tend to fade, as in the case of chronic and long-term care (De Simone, 2011a). In consideration of technology advances, new economic challenges in health care, and the epidemiological trend to long term health status, more specialized health organizations spread (Wright \& Perry).

The theoretical framework based on neo-institutional approach could explain the influence of isomorphic pressures on innovative processes in health care sector. Findings reveal institutional pressures stimulate the development of innovations and organizational learning, the process by which organization must adapt to environmental changes, modifying its behavior to meet both internal and external demands. This concept concerns both the fit of the organization with its environment (strategic matters), and effective implementation of strategies (Kloot, 1997).

The isomorphic pressure of the prospective payment system for health care had effects on the choice of organizational models to adopt. Many hospitals changed the way to organize services, such as the centralization of core health services and the outsourcing of services with high costs, as restaurant, ambulance transport, and chronic disease process. Moreover, other pressures on organizations are made by innovations in medical technology. Hospitals must find ways to increase profit, by improving medical capabilities for payment health care services, such as plastic surgery operations (Yang, Fang, \& Lin, 2010).

Professional competence of managers and physicians, especially in health care processes, and the knowledge of patient demand, represent crucial elements to achieve the competitive advantage (Yang \& Fang, 2007).

The interaction between environment's demands and organization's capabilities can create innovative processes not planned before (involuntary isomorphism). If the hospital organization is able to maintain its legitimacy, the acquisition of knowledge will lead to knowledge creation and ensure that the hospital organization will fit its changing institutional environment. Differently, organizations can decide to imitate other innovator actors to get external legitimacy (voluntary isomorphism).

The institutional pressures create only an apparent conflict between the rationality legitimated by external stakeholders and the internal efficiency that the organization should follow in relation to its specific characteristics. Meyer and Rowan (1977) recognize that organizations often develop two parallel structures, a formal structure to respect the external ceremonials, and an informal structure following the efficiency rules. External interventions are often encouraged by individual organizations, to get social legitimacy to their behavior. The challenge for hospital administrators is to seek consistency between efficiency and quality care.

\section{References}

Abbot, A. (1988). The System of Professions: An Essay on the Division of Expert Labor. Chicago: University of 
Press.

Davis, G. F., Diekmann, K. A., \& Tinsley, C. H. (1994). The decline and fall of the conglomerate firm in the 1980s: A study in the de-institutionalization of an organizational form. American Sociological Review, 59, 547-570.

De Simone, S. (2005). L'impatto dei fattori organizzativi e gestionali sulla qualità dell'assistenza sanitaria, 37. Napoli, Italia: Enzo Albano.

De Simone, S. (2014). A Conceptual Framework for the Organizational Analysis in Health Care Contexts. International Journal of Humanities and Social Science, 4(12), 46-52.

De Simone, S., \& Siani, P. (2015). La qualità della vita lavorativa nelle organizzazioni sanitarie: Risultati di un'indagine empirica. Mondo Sanitario, 2, 35-38.

De Simone, S., (2011a). Logiche istituzionali e performance nelle organizzazioni sanitarie. In M. Franco, \& S. De Simone (Eds.), Organizzazioni sanitarie: dal design al management (pp. 1-32). Milano, Italia: McGraw-Hill.

De Simone, S., (2011b). Cambiamento nelle organizzazioni ospedaliere: meccanismi strutturali e culturali. In M. Franco, \& S. De Simone (Eds.), Organizzazioni sanitarie: Dal design al management (pp. 229-258). Milano, Italia: McGraw-Hill.

DiMaggio, P. J. (1991). Constructing an Organizational Field as a Professional Project. In W. W. Powell, \& P. J. DiMaggio (Eds.), The New Institutionalism in Organizational Analysis (pp. 183-203). Chicago: University of Chicago Press.

DiMaggio, P. J., \& Powell, W. W. (1983). The iron cage revisited: Institutional isomorphism and collective rationality in organizational fields. American Sociological Review, 48, 147-160.

Flood, A. B., \& Fennel, M. L. (1995). Through the lens of organizational sociology: the role of organizational theory and research in conceptualizing and examining our health care system. Journal of Health and Social Behavior, 35(Extra Issue), 154-169.

Friedland, R., \& Alford, R. (1991). Bringing society back in: Symbols, Practices, and institutional contradictions. In W. W. Powell, \& P. J. DiMaggio (Eds.), The New Institutionalism in Organizational Analysis. Chicago: University of Chicago Press.

Galvin, T. L. (2002). Examining institutional change: Evidence from the founding dynamics of U.S. health care interest associations. Academy Management Journal, 45, 58-80. http://dx.doi.org/10.1016/j.ihe.2012.10.014

Giddens, A. (1984). The Constitution of Society. Berkley: University of California Press.

Greenwood, R., \& Hining, C. R. (1988). The Dynamics of Strategic Change. Oxford: Basil Blackwell.

Greenwood, R., \& Hining, C. R. (1996). Understanding radical organizational change: Bringing together the Old and New Institutionalism. Academy of Management Review, 21(4), 1022-1054.

Kloot, L. (1997). Organizational learning and management control systems: responding to environmental change. Management Accounting Research, 8, 47-73.

Meyer, J. W., \& Rowan, B. (1977). Institutionalized Organizations: Formal Structure as Myth and Ceremony. American Journal of Sociology, 83, 340-363.

Oliver, C. (1991). Strategic Responses to Institutional Processes. Academy of Management Review, 16, $145-179$.

Powell, W. W. (1991). Expanding the scope of institutional analysis. In W. W. Powell, \& P. J. DiMaggio (Eds.), The New Institutionalism in Organizational Analysis (pp. 183-203). Chicago: University of Chicago Press.

Powell, W. W., \& DiMaggio, P. J. (1991). The New Institutionalism in Organizational Analysis. Chicago: University of Chicago Press.

Reay, T., \& Hinings, C. R. B. (2015). The Recomposition of an Organizational Field: Health care in Alberta. Organization studies, 26(3), 351-384. http://dx.doi.org/10.1177/0170840605050872.

Scott, W. R. (1987). The Adolescence of Institutional Theory. Administrative Science Quarterly, 32, $493-511$.

Scott, W. R. (1995). Institutions and Organizations. Thousand Oaks, CA: Sage.

Scott, W. R., \& Meyer, J. W. (1983). The organization of Societal Sector. In J. W. Meyer, \& W. R. Scott (Eds.), Organizational Environments: Ritual and Rationality (pp. 129-153). Beverly Hills, CA: Sage. 
Scott, W. R., Mendel, P., \& Pollack, S. (1996, March). Environment and Fields. Studying the Evolution of a Field of Medical Care Organizations. Paper presented at the Conference on Institutional Analysis, University of Arizona.

Selznick, P. (1957). Leadership in administration. New York, NY: Harper-Row.

Williamson, O. E. (1991). Comparative economic organization: The Analysis of discrete structural alternatives. Administrative Science Quarterly, 36, 269-296.

Wright, E. R. \& Brea, L. P. (2010). Medical Sociology and Health Services Research: past accomplishments and Future Policy Challenges. Journal of Health and Social Behavior, 51(S), S107-S119.

Yang, C. W., Fang, S. C. \& Lin, J. L. (2010). Professional knowledge creation in the hospital sector: a qualitative study in Taiwan. International Journal of Health Planning and Management, 25, 169-191. http://dx.doi.org/10.1002/hpm.1002.

Yang, C. W., Fang, S. C. (2007). Isomorphic pressures, institutional strategies, and knowledge creation in the health care sector. Health Care Management Review, 32(3), 263-270. http://dx.doi.org/10.1097/01.HMR.0000281627.22526.ee

Zimmerman, M., \& Zeitz, G. (2002). Beyond survival: achieving new venture growth by building legitimacy. Academy Management Review, 27, 414-431. http://dx.doi.org/10.5465/AMR.2002.7389921

\section{Copyrights}

Copyright for this article is retained by the author(s), with first publication rights granted to the journal.

This is an open-access article distributed under the terms and conditions of the Creative Commons Attribution license (http://creativecommons.org/licenses/by/4.0/). 